\title{
Flexible polytriphenylamine-based cathodes with reinforced energy- storage capacity for high-performance sodium-ion batteries
}

\author{
Lulu $\mathrm{Mo}^{1}$, Gangyong Zhou ${ }^{1}$, Peng Ge $3^{3^{*}}$, Yue-E Miao ${ }^{1^{*}}$ and Tianxi Liu ${ }^{1,2^{*}}$
}

\begin{abstract}
Owing to the excellent redox reversibility and structural diversity, polytriphenylamine (PTPAn) has been regarded as one of the promising cathode candidates for sodium-ion batteries. However, it still suffers from the bulk aggregation and low operating capacity in practical applications. Assisted by the in-situ polymerization, leaf-like PTPAn nanosheets are uniformly introduced on the surface of carbon nanofibers (CNFs) to form the free-standing CNF@PTPAn composite electrodes. Interestingly, the formation mechanism of the leaf-on-branch structure of CNF@PTPAn composites is systematically explored, confirming that the controlling of oxidation rate and growth degree plays crucial roles in tuning the morphology and active material content of the composite electrodes. Supported by the capacity-cutting analysis, the effective coupling between the active PTPAn and conductive CNFs can provide fast electron/ion-shuttling channels and deepen the electrochemical reaction process. At $50 \mathrm{~mA} \mathrm{~g}^{-1}$, the capacity of the optimized CNF@PTPAn composite can reach $105 \mathrm{~mA} \mathrm{~h} \mathrm{~g}^{-1}$, with a stable rate capability of $78 \mathrm{~mA} \mathrm{~h} \mathrm{~g}^{-1}$ even at $400 \mathrm{~mA} \mathrm{~g}^{-1}$ after 500 cycles in a half cell. The detailed kinetic analysis confirms that the ion-storage behaviors in the lowvoltage region can be tailored for the improved capacitive contribution and diffusion coefficients. Meanwhile, the flexible CNF-based full cell with CNF@PTPAn as the cathode and CNFs as the anode exhibits a high energy density of $60 \mathrm{~W} \mathrm{~h} \mathrm{~kg}$-1 at $938 \mathrm{~W} \mathrm{~kg}^{-1}$. Based on this, the rational design is expected to provide more possibilities to obtain advanced freestanding electrode systems.
\end{abstract}

Keywords: polytriphenylamine, carbon nanofibers, electrospinning, organic cathode, flexible sodium-ion batteries

\section{INTRODUCTION}

Attracted by the abundant and low-cost sodium $(\mathrm{Na})$ resources, sodium-ion batteries (SIBs) have been regarded as a promising candidate compared with lithium-ion batteries (LIBs) [1,2]. Nevertheless, they still suffer from the slow kinetics owing to the larger $\mathrm{Na}$ radius [3]. Especially, the cathode materials play vital roles in the sodium-storage capabilities of full cells $[4,5]$. Therefore, exploring advanced cathode materials with both high-rate properties and remarkable durability is of vital importance for SIBs. Some significant progress has been gained on developing advanced cathode materials, including inorganic compounds (e.g., $\mathrm{NaMnO}_{2}, \mathrm{Na}_{3} \mathrm{~V}_{2}\left(\mathrm{PO}_{4}\right)_{3}$ ), small organic molecules (e.g., $\mathrm{Na}_{4} \mathrm{C}_{8} \mathrm{H}_{2} \mathrm{O}_{6}$, PTCDA) and polymers (e.g., polyimides, polyaniline) [6-10]. Among them, inorganic compounds and small-organic molecules are limited by their rigid lattices and high solubility in electrolyte, respectively [11,12]. Fortunately, owing to the merits of open ionic channels and low solubility, polymers have captured numerous attentions, which can deliver stable cyclability and high-rate capability [13-15]. In particular, polytriphenylamine (PTPAn), as a typical conjugated conducting polymer with the unique anion-storage mechanism which is irrespective of the cation nature $\left(\mathrm{Li}^{+}, \mathrm{Na}^{+}\right.$and $\left.\mathrm{K}^{+}\right)$, has been actively investigated as a promising cathode material for SIBs with a considerable theoretical capacity of $109 \mathrm{~mA} \mathrm{~h} \mathrm{~g}^{-1}$ [16-19]. However, the bulk PTPAn electrode suffers from the issues of inevitable agglomeration and poor electronic conductivity, which lead to its low utilization ratio, insufficient delivery capacity and poor rate capability in practical applications.

To address the above problems, one of the effective strategies is to design favorable polymer molecular structure and morphology. Chen et al. [20] reported an interesting micro-/mesoporous structure of PTPAn-derivatives with facilitated electrolyte penetration and sufficient active sites, which exhibited a reversible capacity of $123 \mathrm{~mA} \mathrm{~h} \mathrm{~g}^{-1}$ in LIBs. Another efficient strategy is to combine PTPAn with carbon nanomaterials to obtain composite electrodes with largely improved electronic conductivity, such as PTPAn/carbon nanotube (CNT) composites [21] and PTPAn/active carbon composites [22]. Nevertheless, many studies mainly focus on PTPAn-powder electrodes, which involve a complicated electrode preparation process for the practical applications. Typically, electrically insulating binders and current collectors need to be incorporated, which inevitably reduce the whole battery capacity $[23,24]$. Therefore, free-standing PTPAn-based cathodes with good dispersion and high conductivity are highly desirable for high-performance SIBs.

Inspired by the leaf-on-branch structure of plants, the fully exposed leaves absorb $\mathrm{CO}_{2}$ and solar energy for efficient photosynthesis, while the branches effectively transport the essential nutrients and $\mathrm{H}_{2} \mathrm{O}[25,26]$. Herein, carbon nanofibers (CNFs) have been employed as the supporting branches to construct the

\footnotetext{
${ }^{1}$ State Key Laboratory for Modification of Chemical Fibers and Polymer Materials, College of Materials Science and Engineering, Innovation Center for Textile Science and Technology, Donghua University, Shanghai 201620, China

${ }^{2}$ Key Laboratory of Synthetic and Biological Colloids, Ministry of Education, School of Chemical and Material Engineering, Jiangnan University, Wuxi 214122, China

${ }^{3}$ School of Minerals Processing and Bioengineering, Central South University, Changsha 410083, China

* Corresponding authors (emails: yuee_miao@dhu.edu.cn (Miao Y); txliu@dhu.edu.cn (Liu T); gp-gepeng@csu.edu.cn (Ge P))
} 
flexible CNF@PTPAn composite cathode with leaf-on-branch structures for SIBs, which rationally combines the electrospinning technique and in-situ polymerization processes. Profiting from the effective utilization of active PTPAn and high conductivity of CNFs, the engineered electrode demonstrates fast electron/ion transport and enhanced electrochemical reaction process. It exhibits an initial capacity of $105 \mathrm{mAhg}^{-1}$ at $50 \mathrm{~mA} \mathrm{~g}^{-1}$ and stable rate capability for 500 cycles even at $400 \mathrm{~mA} \mathrm{~g}^{-1}$ in SIBs. Moreover, the flexible CNF@PTPAn//CNF full cell displays a high energy density of $60 \mathrm{Wh} \mathrm{kg}^{-1}$ at $938 \mathrm{~W} \mathrm{~kg}^{-1}$, being a promising candidate for the flexible sodiumion storage devices.

\section{EXPERIMENTAL SECTION}

\section{Materials}

p-Phenylenediamine (PDA), pyromellitic dianhydride (PMDA), triphenylamine (TPAn), $\mathrm{H}_{2} \mathrm{SO}_{4}$ and $\mathrm{FeCl}_{3}$ (AR grade) were obtained from aladdin. N,N-dimethylformamide (DMF), methanol and $\mathrm{CHCl}_{3}$ were purchased from Sinopharm Chemical Regent. All these chemicals were used as received without further purification except otherwise noted.

\section{Synthesis of CNF@PTPAn composite fiber membranes}

The CNF@PTPAn composites with a three-dimensional (3D) network structure were synthesized by in-situ polymerization of TPAn on the flexible carbon nanofiber membranes. First, the flexible carbon nanofiber membrane was prepared through the electrospinning and carbonization process. Typically, $0.1 \mathrm{~mol}$ of PDA, $0.1 \mathrm{~mol}$ of PMDA and $30 \mathrm{~mL}$ of DMF were added into a flask with magnetic stirring at room temperature. Then, the polyamide acid (PAA) precursor was obtained via polymerization of the reaction mixture at $0^{\circ} \mathrm{C}$ for $12 \mathrm{~h}$ under $\mathrm{N}_{2}$ atmosphere. Subsequently, the PAA solution was transferred into a 10 -mL plastic syringe with a stainless-steel needle of 21-gauge blunt-tip and pushed by a positive voltage of $20 \mathrm{kV}$ with a flow rate of $0.1 \mathrm{~mm} \mathrm{~min}^{-1}$. Meanwhile, the distance between the needle and Al-foil collector was about $20 \mathrm{~cm}$. The as-spun PAA fiber membrane was removed from the $\mathrm{Al}$-foil and dried at $60^{\circ} \mathrm{C}$ for $12 \mathrm{~h}$ in air atmosphere. Then, the dried PAA fiber membrane was imidized at $300^{\circ} \mathrm{C}$ for $2 \mathrm{~h}$ in $\mathrm{N}_{2}$ atmosphere to form polyimide (PI) membrane, and subsequently carbonized at $1000^{\circ} \mathrm{C}$ for $2 \mathrm{~h}$ with a heating rate of $5^{\circ} \mathrm{C} \mathrm{min}^{-1}$ to obtain the flexible CNF membrane.

The CNF@PTPAn composite membranes were prepared using a modified chemical oxidative method according to previous reports $[27,28]$. TPAn monomer $(6 \mathrm{mmol})$ was dissolved in $50 \mathrm{~mL}$ of $\mathrm{CHCl}_{3}$ with magnetic stirring. Then, $\mathrm{CNF}$ slices were immersed in the solution for $30 \mathrm{~min}$ to allow for sufficient wetting. After that, $12 \mathrm{mmol}$ of $\mathrm{FeCl}_{3}$ (molar ratio $=2: 1$ to TPAn) were added to induce the in-situ polymerization of TPAn at $50^{\circ} \mathrm{C}$ for $8 \mathrm{~h}$ in $\mathrm{N}_{2}$ atmosphere. The reaction products were poured into methanol to precipitate and then washed with methanol and deionized water, and finally dried in vacuum at $60^{\circ} \mathrm{C}$ for $12 \mathrm{~h}$ to obtain the CNF@PTPAn-1 composite membrane. Meanwhile, CNF@PTPAn-2 and CNF@PTPAn-3 composite membranes were obtained with different molar ratios (4:1 and 6:1) between $\mathrm{FeCl}_{3}$ and TPAn, respectively. Besides, CNF@PTPAn-2A and CNF@PTPAn-2A' composite membranes were acquired by changing the added contents ( 3 and $8 \mathrm{mmol}$ ) of TPAn at a fixed $\mathrm{FeCl}_{3}:$ TPAn ratio of $4: 1$. For comparison, the pure PTPAn powder was synthesized in the absence of CNFs via the above similar procedure with a fixed $\mathrm{FeCl}_{3}$ :TPAn ratio of $4: 1$ and TPAn content of $6 \mathrm{mmol}$.

\section{Characterizations}

Fourier transform infrared (FT-IR) spectra of the prepared samples were recorded on a Thermo Fisher Nicolet6700 FT-IR spectrometer with $\mathrm{KBr}$ pellets. X-ray diffraction (XRD) data of the obtained products were acquired by a Rigaku $\mathrm{D} / \mathrm{Max} 2550 \mathrm{VB}+/ \mathrm{PC} \mathrm{X}$-ray diffractometer with $\mathrm{Cu}-\mathrm{Ka}$ radiation. Raman spectra were carried out on a Renishaw inVia-Reflex spectrometer with a $532-\mathrm{nm}$ laser line. Solid state ${ }^{13} \mathrm{C}$ nuclear magnetic resonance $\left({ }^{13} \mathrm{C} \mathrm{NMR}\right)$ was performed on a Bruker Avance 400 spectrometer at $101 \mathrm{MHz}$. Morphologies of the assynthesized products were studied by a JEOL JSM-7001F fieldemission scanning electron microscope (FESEM). The X-ray photoelectron spectroscopy (XPS) measurements were performed by a Thermo ESCALAB 250Xi spectrometer. Tensile tests were performed using a SUNS UTM2102 machine with a strain rate of $2 \mathrm{~mm} \mathrm{~min}^{-1}$. Contact angle measurements were conducted using the OCA40 Micro Contact Angle Meter at room temperature using the liquid electrolyte of $1 \mathrm{~mol} \mathrm{~L}^{-1}$ $\mathrm{NaClO}_{4}$ in ethylene carbonate (EC) and dimethyl carbonate (DMC) (1:1, by volume ratio) with $5 \mathrm{wt} \%$ fluoroethylene carbonate (FEC) as the additive. The average electrical conductivity of the membranes was tested by a four-point probe method using an RTS-8 four-probe meter. Brunauer-Emmett-Teller (BET) specific surface area was measured by an ASAP 2020 analyzer based on the $\mathrm{N}_{2}$ adsorption-desorption isotherms.

\section{Electrochemical measurements}

The as-prepared CNF@PTPAn composite membranes can be directly used as the cathode without additional conductive carbon, binder and current collector. The mass loading of active PTPAn in the CNF@PTPAn composite membranes were measured by the mass difference between CNFs and CNF@PTPAn membranes after in-situ polymerization reactions. For comparison, the conventional casting electrode of PTPAn powder was also prepared, which was signed as PTPAn-C. Typically, the powder PTPAn (60 wt\%), super P (30 wt\%) and polyvinylidene fluoride (PVDF) binder (10 wt\%) were mixed in 1-methyl-2pyrrolidinone (NMP) into slurry, coated on $\mathrm{Al}$ foil, and then dried at $80^{\circ} \mathrm{C}$ in vacuum to remove the solvent. The specific mass loading of active materials for different samples was provided in Table S1.

CR2032 coin cells were assembled in an argon-filled glove box (Mikrouna Universal) with glass fiber as the separator and $1 \mathrm{~mol} \mathrm{~L}^{-1} \mathrm{NaClO}_{4}$ in EC/DMC (1:1, by volume ratio) with $5 \mathrm{wt} \%$ FEC as the electrolyte. For the half cell assembly, sodium metal was used as the counter-electrode. Galvanostatic charge-discharge (GCD) measurements were performed using LANDCT2001A battery test instrument between 2.0 and $4.0 \mathrm{~V}$. The cyclic voltammetry $(\mathrm{CV})$ and electrochemical impedance spectroscopy (EIS) tests were recorded by a CHI660E electrochemical workstation in the voltage range of $2.5-4.0 \mathrm{~V}$ at different scan rates and in the frequency range from $100 \mathrm{kHz}$ to $10 \mathrm{mHz}$ with a voltage amplitude of $\pm 5 \mathrm{mV}$ at open circuit voltage, respectively.

In full cells, CNF was used as the anode. Before the electrodes were assembled into full cells, both of CNF@ PTPAn-2 and CNF electrodes were processed for three charge/discharge cycles in 
half cells to avoid cycling activation and irreversible capacity loss [29]. The CNF@PTPAn//CNF full cell was assembled based on the mass ratio of $0.6: 1$ between the CNF anode and PTPAn cathode. The electrochemical performance was evaluated in the voltage range of $0.01-3.5 \mathrm{~V}$. All electrochemical tests were conducted at room temperature.

\section{RESULTS AND DISCUSSION}

\section{Physical-chemical properties of CNF@PTPAn composite} membranes

The CNF@PTPAn composite membranes, with an ideal leaf-onbranch structure, were prepared by the in-situ polymerization of PTPAn on CNFs as shown in Fig. 1a. First, the CNF membrane with unique $3 \mathrm{D}$ fibrous network and high conductivity was facilely obtained through the combination of electrospinning and carbonization [30,31]. Then, TPAn monomer molecules were adsorbed on the exposed surface sites of CNFs and further polymerized into the active PTPAn through the chemical polymerization processes schemed in Fig. S1. The solid-state ${ }^{13} \mathrm{C}$ NMR spectrum of PTPAn displays main characteristic bands of aromatic region at $146.61,135.11,127.38$ and $124.38 \mathrm{ppm}$, indicating a systematic shift compared with those of the TPAn monomer (Fig. 1b). In the XRD patterns (Fig. 1c), the TPAn monomer shows a series of strong crystal diffraction peaks. After polymerization, there is only one main broad peak at about $2 \theta=$ $20^{\circ}$ for the as-prepared PTPAn, demonstrating its amorphous structure [28]. For the CNF@PTPAn composite membrane, two weak broad bands located around $2 \theta=20^{\circ}$ and $25^{\circ}$ are observed, which are ascribed to the amorphous PTPAn and CNFs, respectively [32]. To further confirm the detailed structure of PTPAn in the CNF@PTPAn composite, Raman spectra were carried out. As shown in Fig. 1d, there are obvious absorption changes from the TPAn monomer to PTPAn polymer. The typical peaks at 996 and $1025 \mathrm{~cm}^{-1}$, assigned to the mono-substituted rings of TPAn, disappear while the characteristic peaks derived from $\mathrm{C}=\mathrm{C}$ ring stretching, $\mathrm{C}-\mathrm{N}$ stretching and $\mathrm{C}-\mathrm{H}$ bending vibration of benzenoid rings shift to 1600,1300 and $1115 \mathrm{~cm}^{-1}$, respectively, indicating the formation of PTPAn $[33,34]$. In addition, the bare CNF membrane shows two typical peaks at $1352 \mathrm{~cm}^{-1}$ (D-band) and $1588 \mathrm{~cm}^{-1}$ (G-band), corresponding to the disordered graphite structure and the $\mathrm{E}_{2 \mathrm{~g}}$ vibration of graphitic carbon with a $\mathrm{sp}^{2}$ electronic configuration, respectively [35]. Nevertheless, the characteristic peaks of CNFs are not observed in the CNF@PTPAn composite membrane, which may be because that the surface of CNFs is covered by PTPAn with high-intensity Raman responses. Moreover, the FTIR spectrum of CNF@PTPAn shows a series of peaks at 1592, 1490,1324 and $1277 \mathrm{~cm}^{-1}$ (Fig. 1e), which are attributed to the $\mathrm{C}=\mathrm{C}$ ring stretching, $\mathrm{C}-\mathrm{C}$ stretching, $\mathrm{C}-\mathrm{H}$ bending and $\mathrm{C}-\mathrm{N}$
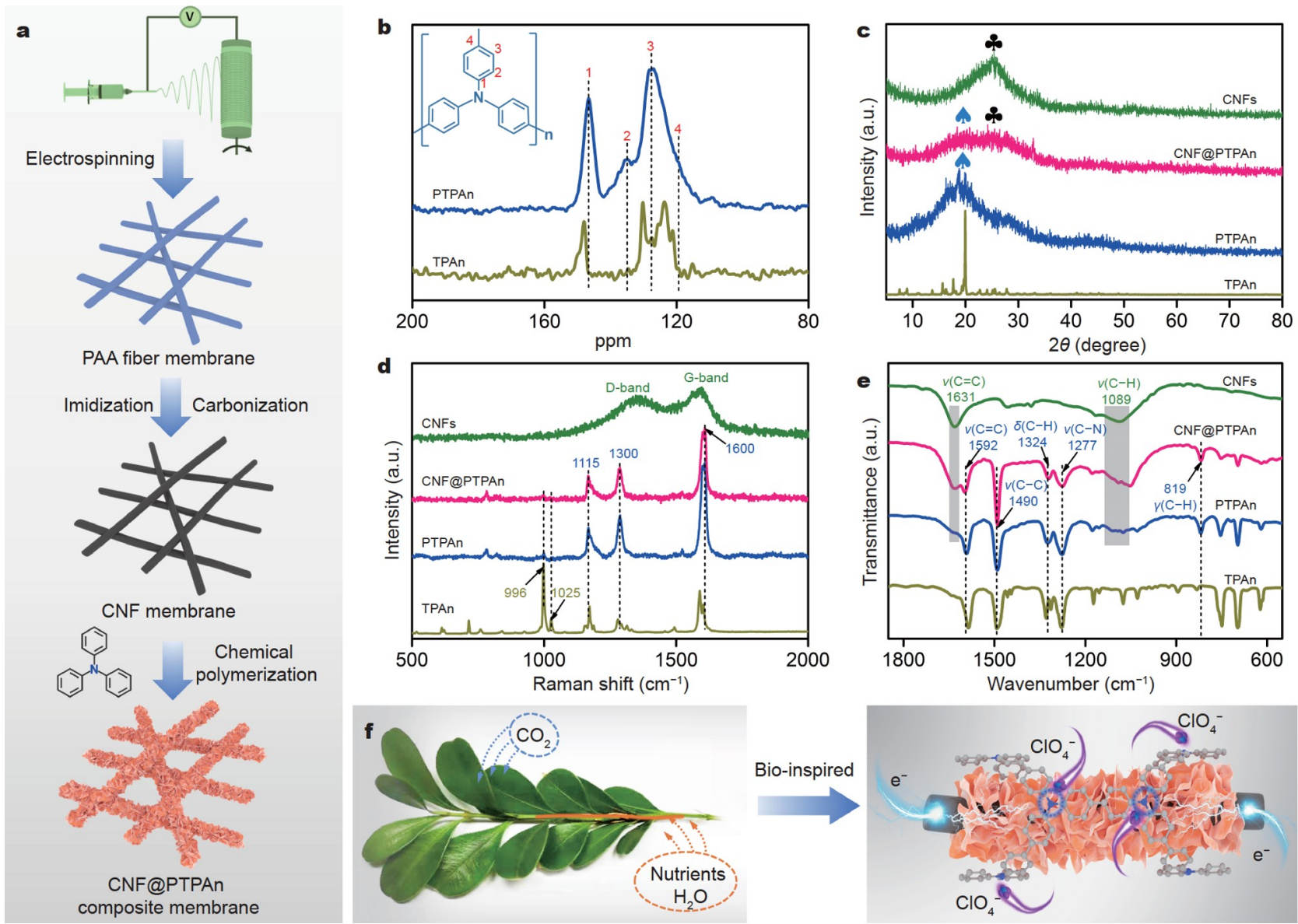

Figure 1 (a) Schematic illustration of the preparation process for CNF@PTPAn composite membrane. (b) ${ }^{13} \mathrm{C}$ NMR spectra of TPAn monomer and PTPAn powder. (c) XRD patterns, (d) Raman spectra and (e) FT-IR spectra of TPAn monomer, PTPAn, CNFs and CNF@PTPAn. (f) Design concept of CNF@PTPAn composite membrane. 
stretching of TPAn, respectively. Simultaneously, a new peak appears at $819 \mathrm{~cm}^{-1}$ in the $\mathrm{C}-\mathrm{H}$ out-of-plane vibrations region, indicating that the structural unit of TPAn is connected by parasubstituted benzene rings to form PTPAn $[16,36]$. These results further confirm that PTPAn has been successfully grown on CNFs by rational design. Similar to the photosynthesis of plants, the bio-inspired CNF@PTPAn composite membrane could be an ideal structure as the free-standing cathode for high-performance SIBs. As shown in Fig. 1f, the exposed PTPAn-leaves can capture plenty of ions, while CNF-branches provide effective electronic channels, thus endowing the favorable high electron and ion conductivity.

For the practical applications of the as-resulted composite membrane, the electrolyte wettability and mechanical property were investigated. As shown in Fig. S2a, the electrolyte contact angle of CNF@PTPAn membrane is about $16.3^{\circ}$, smaller than that of the casting PTPAn-C electrode $\left(33.5^{\circ}\right)$, confirming the better electrolyte wettability of CNF@PTPAn, which results from the particular 3D network structure of CNFs. Meanwhile, the specific surface area of CNF@PTPAn is detected as $33.03 \mathrm{~m}^{2} \mathrm{~g}^{-1}$ (Fig. S2b, c), rendering its enhanced penetration in the electrolyte $[37,38]$. The electrical conductivity of the PTPAnC electrode, CNF and CNF@PTPAn composite membranes were further explored (Fig. S3). With a high calcination temperature over $1000^{\circ} \mathrm{C}$, the as-prepared $\mathrm{CNF}$ membrane shows an excellent conductivity of $4.6 \mathrm{~S} \mathrm{~cm}^{-1}$ as the conductive support for PTPAn. As expected, the conductivity of CNF@PTPAn still maintains $2 \mathrm{~S} \mathrm{~cm}^{-1}$ which is much higher than that of the casting PTPAn-C electrode $\left(0.36 \mathrm{~S} \mathrm{~cm}^{-1}\right)$, giving rise to the faster charger transfer [39]. From the mechanical analysis (Fig. S4), good structural stability and high flexibility are found for the CNF membrane, which reaches a maximal tensile break strength of $1.56 \mathrm{MPa}$ with a tensile strain close to $7.21 \%$. Interestingly, owing to the introduction of CNFs, the as-resulted CNF@PTPAn composite membrane also displays a good flexible property with a tensile break strength of $1.39 \mathrm{MPa}$ and tensile strain of $6.17 \%$, further confirming its potentials in advanced flexible energy-storage fields.

\section{Morphological optimization of CNF@PTPAn composite membranes}

Considering the effect of morphology on electrochemical properties, the detailed structural evolution of CNF@PTPAn was investigated (Fig. 2). Through the controlling of molar ratio of oxidant/monomer $\left(\mathrm{FeCl}_{3}: \mathrm{TPAn}\right)$, a series of CNF@PTPAn composite membranes were prepared. Interestingly, the CNF membrane displays a $3 \mathrm{D}$ network structure with fiber diameter of 200-400 nm (Fig. 2a), where the existing sites on the CNF surface are beneficial to the growth of PTPAn-leaves. After polymerization reactions, different morphologies of PTPAnleaves are grown on the CNF-branches with the corresponding contents of PTPAn given in Table S1. As for CNF@PTPAn-1, a small content (6 wt\%) of spherical-shaped PTPAn are distributed on the surface of CNFs (Fig. 2b), which may be because that the polymerization of PTPAn is not incomplete at a low oxidant/monomer ratio $\left(\mathrm{FeCl}_{3}: \mathrm{TPAn}=2: 1\right)$. When the $\mathrm{FeCl}_{3}$ : TPAn ratio increases to 4:1, PTPAn nanosheets are densely coated on the CNF skeletons with a high mass loading of $45 \mathrm{wt} \%$ and randomly assembled into a unique porous structure (Fig. 2c). However, as the ratio reaches 6:1 (Fig. 2d), PTPAn nanosheets, with a loading content of only $14 \mathrm{wt} \%$ in the
CNF@PTPAn-3 composite, are inclined to self-aggregation, perhaps due to the too fast polymerization rate. The detailed formation mechanism of CNF@PTPAn with the leaf-on-branch structure is proposed in Fig. 2e. The CNF membrane with the $3 \mathrm{D}$ network structure is well dispersed in the TPAn monomer solution, which can effectively adsorb TPAn monomers on the plentiful sites of CNFs. Then, TPAn monomer molecules are initiated by the oxidizing agent and first converted into PTPAn with low polymerization degree (LPD), and gradually form PTPAn with high polymerization degree (HPD). Finally, PTPAn-leaves successfully grow on the surface of CNF-branches with an ideal porous structure, efficiently inhibiting the aggregation of PTPAn particles (Fig. S5) and facilitating the conductivities of electrons and ions.

Subsequently, the cycling stabilities of CNF@PTPAn composite cathodes at $50 \mathrm{~mA} \mathrm{~g}^{-1}$ in the voltage range of $2.0-4.0 \mathrm{~V}$ are exhibited in Fig. 2f. Obviously, the CNF membrane as the cathode does not contribute to the capacity, only playing the role of supporting the PTPAn-leaves and providing electron pathway for CNF@PTPAn composite cathodes. All the CNF@PTPAn composites exhibit similar shapes of charge/discharge curves with a quite high voltage of $\sim 3.6 \mathrm{~V}$, indicating the doping/ dedoping reactions of the active PTPAn [16]. In addition, the discharge capacities of CNF@PTPAn-1, CNF@PTPAn-2 and CNF@PTPAn-3 are about 114, 95 and $78 \mathrm{mAhg}^{-1}$ at the 1 st cycle (Fig. 2g), respectively. After 100 cycles, their capacities can be kept at 75, 91 and $71 \mathrm{mAhg}^{-1}$ (Fig. 2h). Notably, the CNF@PTPAn-2 cathode not only demonstrates a high initial discharge capacity but also a considerably good cycle stability, which may be ascribed to the ideal morphology feature at the optimal oxidant/monomer ratio of $4: 1$. The capacity of CNF@PTPAn-1 has a rapid fading along with the charge/discharge cycling, owing to the instability of active PTPAn obtained under the low degree of polymerization at the low oxidant ratio. When the oxidant ratio is too high, the self-aggregation of PTPAn leads to its partial falling from the carbon nanofibers and disconnection of the effective electron pathway in the CNF@PTPAn-3 cathode, which results in the low utilization and capacity contribution of PTPAn.

Given the optimal oxidant/monomer ratio, another factor of TPAn monomer concentration was investigated (Fig. S6). With the increasing dosage of TPAn from 3, 6 to $8 \mathrm{mmol}$, the size of PTPAn-leaves becomes larger (Fig. S6a-d), while the mass loading of PTPAn in CNF@PTPAn gradually rises from 32, 45 to $60 \mathrm{wt} \%$. Interestingly, PTPAn still keeps sheet-like morphology, indicating the monomer concentration mainly affects the active material content in CNF@PTPAn composites. Then, the cycling performances of CNF@PTPAn-2 with different mass loadings of PTPAn were evaluated (Fig. S6e). It can be observed that the capacities of all the electrodes show an obvious increase during the first few cycles, which may be ascribed to their electrochemical activation process. After about five cycles, the discharge capacities of CNF@PTPAn-2A, CNF@PTPAn-2, CNF@PTPAn-2A' reach 109, 105 and $94 \mathrm{~mA} \mathrm{~h} \mathrm{~g}^{-1}$, respectively. However, along with cycling, the capacity of CNF@PTPAn-2A (TPAn $=3 \mathrm{mmol}$ ) exhibits obvious decay, in which the grown PTPAn-leaves are inadequate and could not self-assemble into stable porous structure, leading to the damage of electrode structure during the long charge/discharge process. Therefore, the morphological structure and active material mass are optimal with the oxidant ratio of $4: 1$ and TPAn dosage of $6 \mathrm{mmol}$ for 

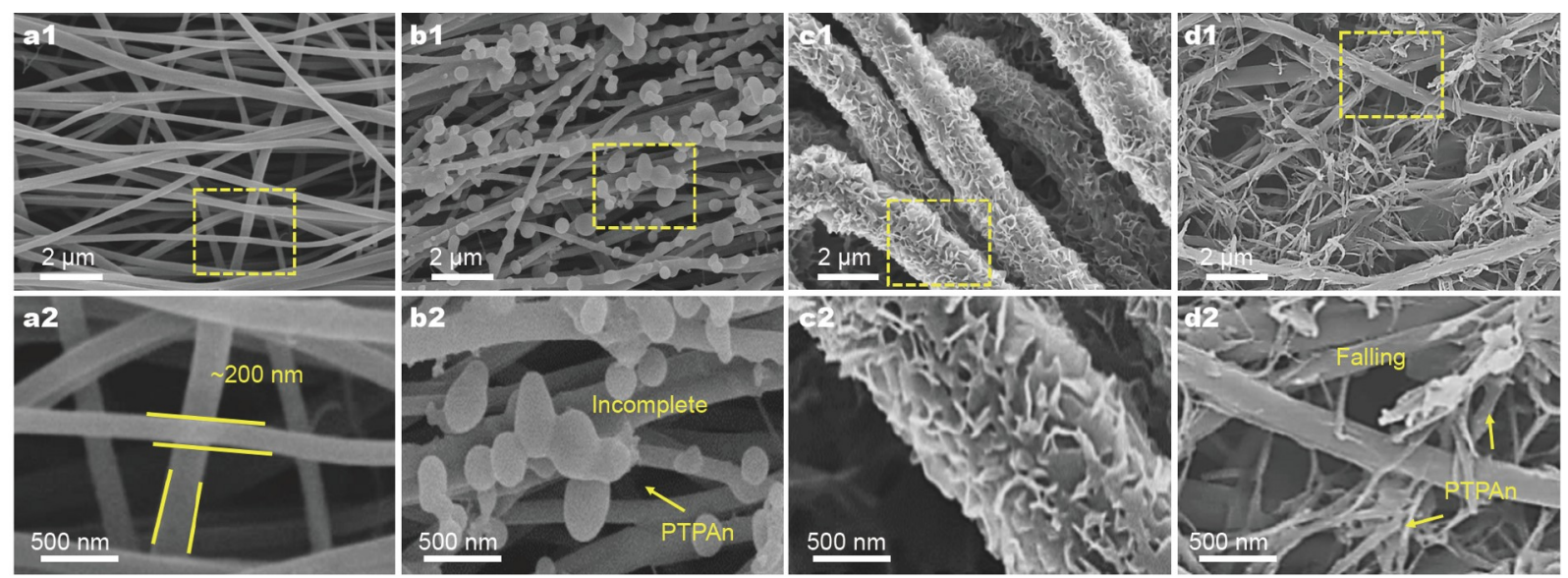

e
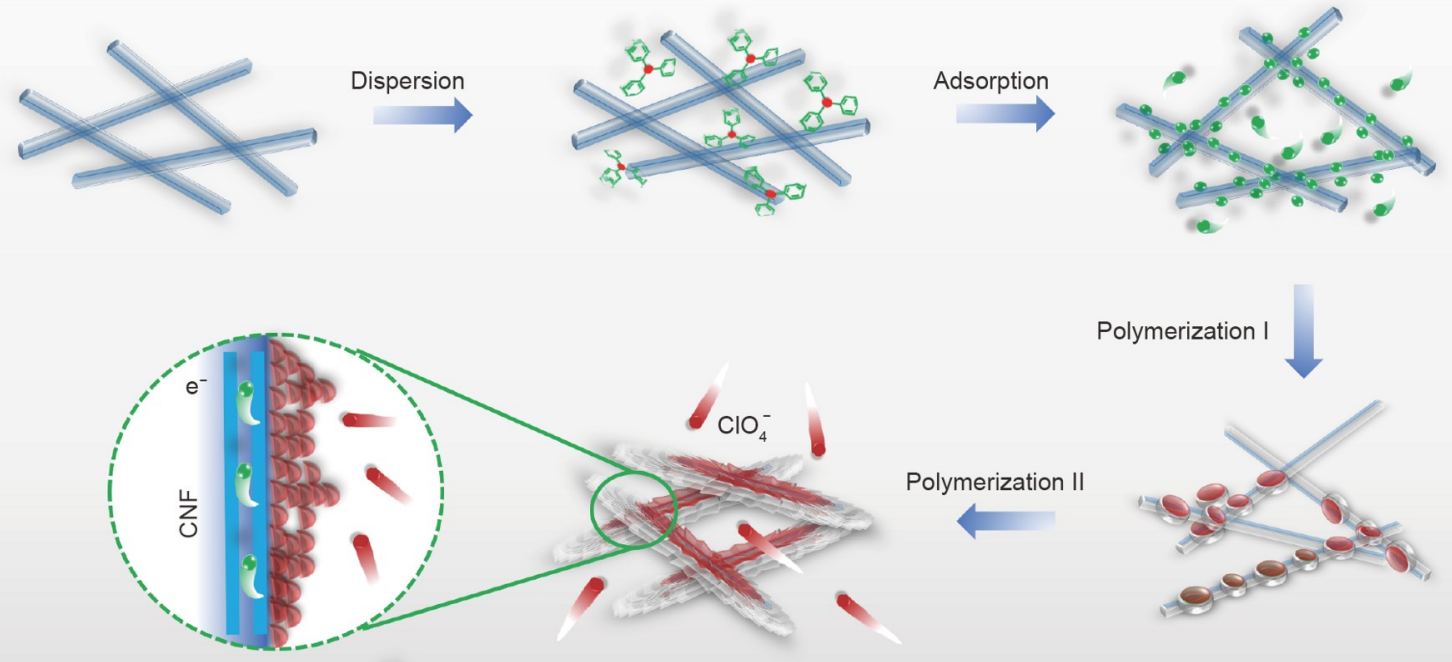

Polymerization I
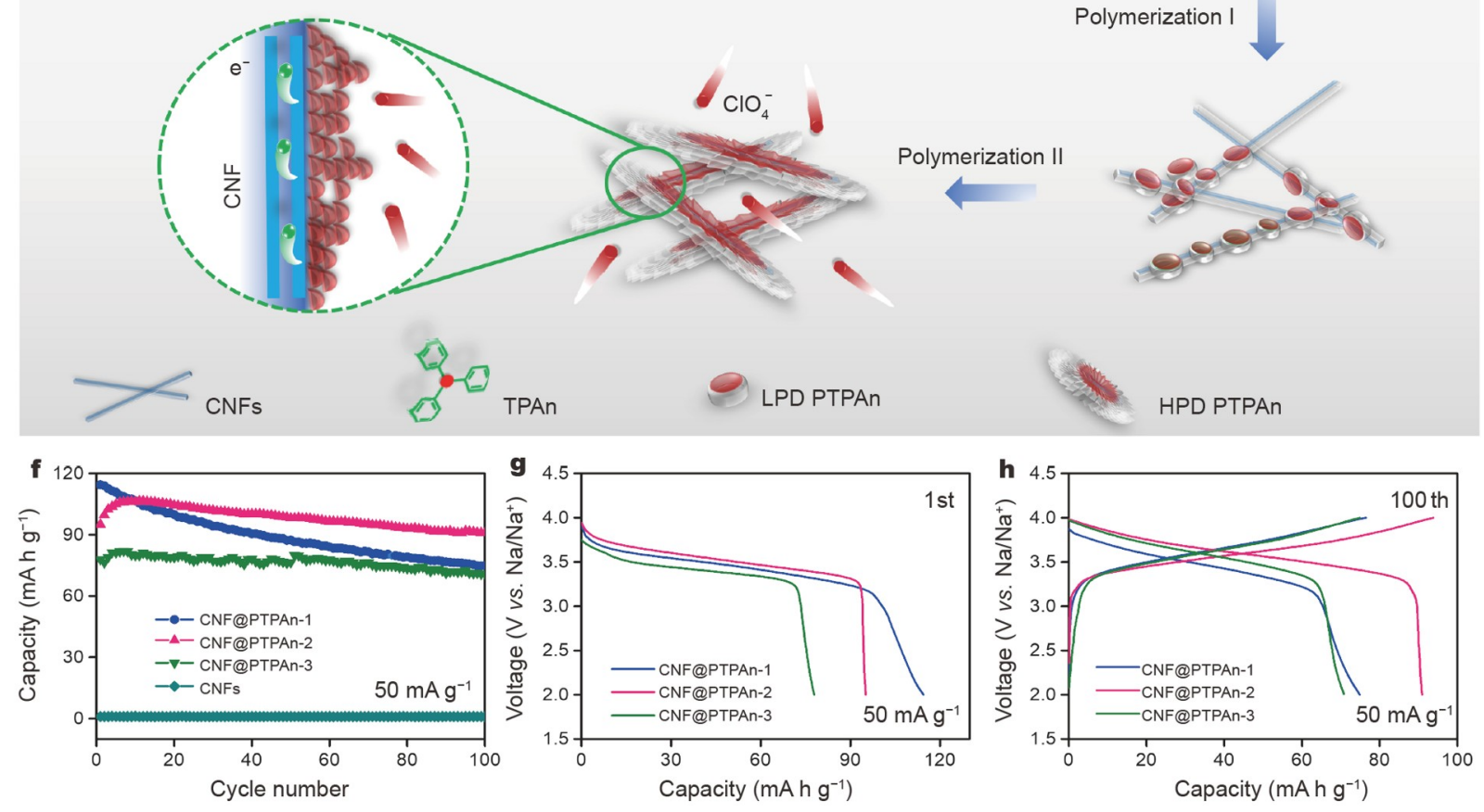

Figure 2 SEM images at different magnifications for (a) bare CNFs, (b) CNF@PTPAn-1 (2:1), (c) CNF@PTPAn-2 (4:1) and (d) CNF@PTPAn-3 (6:1). (e) The in-situ growth mechanism of PTPAn on CNFs. (f) Comparison of cycling performance, and the corresponding voltage curves at the (g) 1st, (h) 100th cycles for the CNF@PTPAn electrodes.

CNF@PTPAn-2, where PTPAn nanosheets are stable and uniform on the surface of CNFs. For comparison, the capacity of the casting PTPAn-C is obtained to be only $80 \mathrm{~mA} \mathrm{~h} \mathrm{~g}^{-1}$ after 100 cycles (Fig. S6f). In contrast, the CNF@PTPAn-2 electrode exhibits improved reversible capacity and cycling stability with $91 \mathrm{~mA} \mathrm{~h} \mathrm{~g}^{-1}$ after 100 cycles (Fig. S6g), suggesting that the freestanding CNF@PTPAn-2 electrode with ideal structure can serve as an effective cathode for SIBs.

The rate performance of the free-standing CNF@PTPAn-2 cathode was also evaluated. As shown in Fig. 3a, the
CNF@PTPAn-2 cathode delivers excellent reversible capacities at various current densities and still keeps $97 \mathrm{~mA} \mathrm{~h} \mathrm{~g}^{-1}$ even at $400 \mathrm{~mA} \mathrm{~g}^{-1}$, much higher than that of PTPAn-C $\left(80 \mathrm{~mA} \mathrm{~h} \mathrm{~g}^{-1}\right)$. In Fig. $3 b$ and $c$, with the increase of current densities, the charge/discharge curves of CNF@PTPAn-2 exhibit much smaller changes than those of PTPAn-C, indicating its superior rate capability. Moreover, by using the initial capacity at $50 \mathrm{~mA} \mathrm{~g}^{-1}$ as the standard value, the capacity retention of CNF@PTPAn-2 maintains around $92 \%$ at $400 \mathrm{~mA} \mathrm{~g}^{-1}$, much higher than that of PTPAn-C (85\%) (Fig. 3d). Compared with the capacity of 

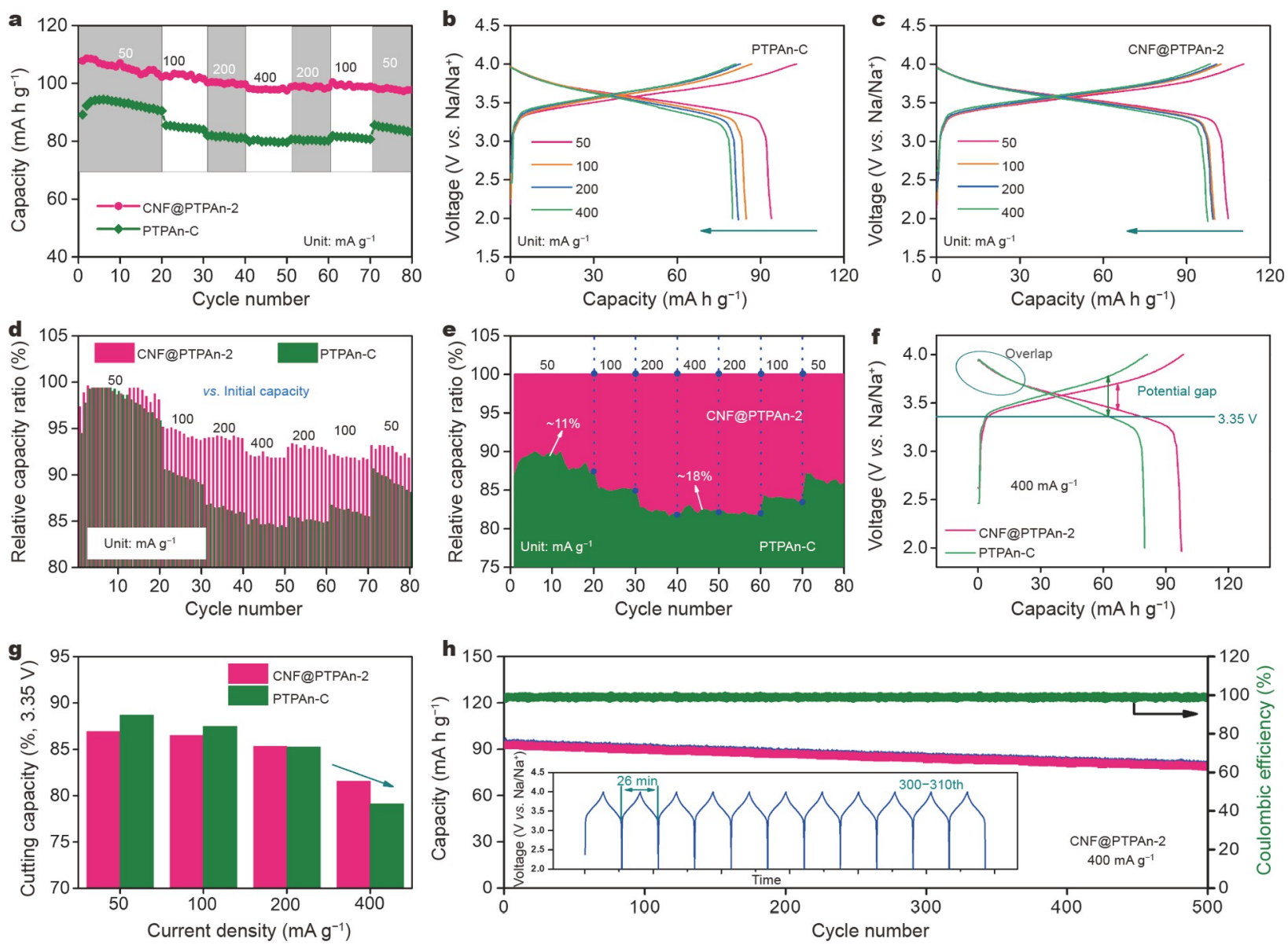

Figure 3 (a) Rate performance, and the corresponding charge/discharge curves of (b) PTPAn-C and (c) CNF@PTPAn-2 at various current densities. (d) Comparison of the capacity retention ratios between PTPAn-C and CNF@PTPAn-2. (e) The relative capacities of PTPAn-C/CNF@PTPAn-2. (f) Comparison of charge/discharge curves between PTPAn-C and CNF@PTPAn-2 at $400 \mathrm{mAg}^{-1}$. (g) Cutting capacity analysis. (h) Cycling performance of CNF@PTPAn-2 at $400 \mathrm{~mA} \mathrm{~g}{ }^{-1}$.

CNF@PTPAn-2, PTPAn-C has a large capacity loss of $18 \%$ at $400 \mathrm{~mA} \mathrm{~g}^{-1}$ (Fig. 3e), which further confirms the excellent rate capability of CNF@PTPAn-2. From the charge/discharge curves of the two electrodes at $400 \mathrm{~mA} \mathrm{~g}^{-1}$ (Fig. 3f), it can be clearly observed that the potential gap of CNF@ PTPAn-2 $(0.26 \mathrm{~V})$ is smaller than that of PTPAn-C $(0.55 \mathrm{~V})$, indicating its fast electrochemical-kinetics. According to the previous studies, the capacity of PTPAn is primarily derived from the electrochemical reaction in the range of $4.0-3.35 \mathrm{~V}$. To give insight into the reason for the improved capacity in CNF@PTPAn-2, the discharge capacity contribution was calculated by cutting capacity analysis (Fig. 3g). It can be found that with the increasing current densities from 50 to $400 \mathrm{~mA} \mathrm{~g}^{-1}$, the discharge capacity contribution of CNF@PTPAn-2 shows a small decrease from $86.9 \%$ to $81.5 \%$. Notably, at the high current density of $400 \mathrm{~mA} \mathrm{~g}^{-1}$, the discharge capacity contribution of CNF@PTPAn-2 (81.5\%) is still higher than that of the PTPAn-C electrode (79.1\%), which suggests that the maximum electrochemical reaction could be induced by the rapid ion/electron transfer in CNF@PTPAn-2 with the unique leaf-on-branch structure. Impressed by the excellent rate capability of CNF@PTPAn-2 at stepwise current rates, its high-rate cycling performance was further evaluated. As presented in Fig. 3h, even at a high current density of $400 \mathrm{mAg} \mathrm{g}^{-1}$, CNF@PTPAn-2 still remains a capacity of $78 \mathrm{mAhg}^{-1}$ after 500 cycles. By the detection of the platforms from the 300th to 310th cycle (the inset of Fig. 3h), the charge/discharge process can complete within just about $26 \mathrm{~min}$, demonstrating the fast charge transfer. Moreover, the higher rate performances of CNF@PTPAn-2 and PTPAn-C were further tested at $1200 \mathrm{mAg}^{-1}$ (Fig. S7). Obviously, CNF@PTPAn-2 still shows a high reversible capacity of $89 \mathrm{~mA} \mathrm{hg}^{-1}$ and remains $74 \mathrm{mAhg}^{-1}$ with a corresponding capacity retention ratio of $83 \%$ after 500 cycles, which is much better than those of PTPAn-C $\left(56 \mathrm{mAhg}^{-1}, 78 \%\right)$. The above electrochemical tests demonstrate that the CNF@PTPAn-2 cathode has an excellent electrochemical performance, compared with most of the previous reports on polymer cathodes as listed in Table S2.

\section{Detailed kinetic behaviors of CNF@PTPAn cathode}

Captured by the excellent electrochemical properties, the detailed kinetic analysis is necessary for revealing the in-depth reasons. Fig. 4a shows the $\mathrm{CV}$ curves of the electrodes at a scan rate of $0.5 \mathrm{mV} \mathrm{s}^{-1}$. The CNF@PTPAn-2 cathode presents an oxidative peak (Peak-1, 3.61 V) and two reductive peaks (Peak-2, $3.54 \mathrm{~V}$ and Peak-3, 3.22 V), accompanying with the doping/ dedoping reactions of electrolyte anions into/from PTPAn polymer chains $[17,28]$. Notably, the Peak- 3 is broadened from $0.19 \mathrm{~V}$ of PTPAn-C to $0.25 \mathrm{~V}$ of CNF@PTPAn-2, illustrating the increased delivery capacity. Generally, the region of Peak-3 at 

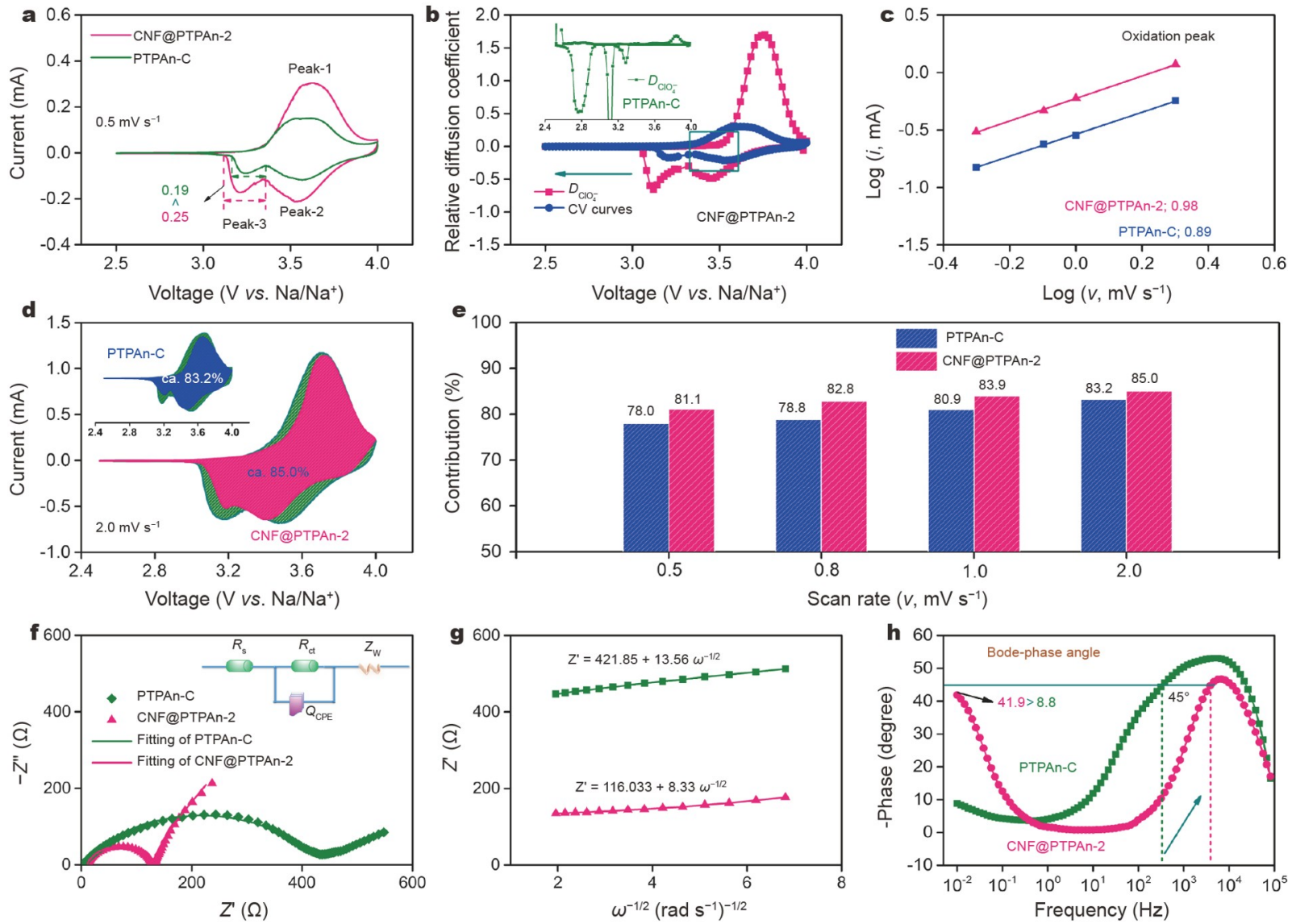

Figure 4 The kinetics analysis of the CNF@PTPAn cathode. (a) Comparisons of CV curves at a scan rate of $0.5 \mathrm{mV} \mathrm{s}^{-1}$, (b) relative diffusion coefficients and (c) linear fitting of $\log (i) v s . \log (v)$ for PTPAn-C and CNF@PTPAn-2. (d) Pseudo-capacitive contribution (pink for CNF@PTPAn-2 and blue for PTPAn-C) and diffusion-controlled contribution (green) at $2.0 \mathrm{mV} \mathrm{s}^{-1}$. (e) Comparison of pseudo-capacitive contribution ratios with the increasing scan rates between PTPAn-C and CNF@PTPAn-2. (f) EIS plots, (g) $Z^{\prime} v s . \omega^{-1 / 2}$ plots, and (h) Bode-phase angle plots of PTPAn-C and CNF@PTPAn-2.

the low voltage is regarded as the slow electrochemical reaction process. In the casting PTPAn-C electrode, the reduction reaction is easy for the active material closing to the current collector, but it is difficult for the residual part due to the long electron transport pathway. By contrast, the CNF@PTPAn-2 cathode possesses rapid electronic channels provided by CNFs, which can promote the reduction reaction rate induced by the sufficient number of electrons. In Fig. S8a and b, with the increasing of scan rate, the response current becomes higher, reflecting that the increased redox reactions bring about more electrons shuttling in the external circuit [40]. According to their corresponding CV curves at different scan rates $(v)$, the linear fitting of peak current ( $i_{\mathrm{p}}$, from Peak-1 and Peak-2) vs. $v^{1 / 2}$ are obtained (Fig. S8c). As a result, the ion diffusion coefficients $(D)$ are also calculated based on Equation (1):

$i_{\mathrm{p}}=2.69 \times 10^{5} n^{3 / 2} A D^{1 / 2} v^{1 / 2} C$,

wherein, $A, n$ and $C$ refer to the electrode area, the number of electrons transferred and the concentration of anion ions in the electrolyte, respectively. By calculation, the oxidation and reduction $D$ values of CNF@PTPAn-2 are $8.66 \times 10^{-10}$ and 2.74 $\times 10^{-10} \mathrm{~cm}^{2} \mathrm{~s}^{-1}$, respectively, whereas those for PTPAn-C are 4.60 $\times 10^{-10}$ and $2.54 \times 10^{-10} \mathrm{~cm}^{2} \mathrm{~s}^{-1}$, respectively. The large $D$ values for CNF@PTPAn-2 indicate the rapid ion diffusion during the electrochemical reactions, which can be attributed to the increased contact area between PTPAn-leaves and electrolyte ions. Meanwhile, the relative diffusion coefficients $\left(D_{\mathrm{ClO}_{4}^{-}}\right)$at different voltage regions were calculated (Fig. 4b). For the PTPAn-C electrode (green curve), the $D_{\mathrm{ClO}_{4}^{-}}$value presents obvious fluctuations, indicating an unstable redox reaction process. The $D_{\mathrm{ClO}_{4}^{-}}$value of CNF@PTPAn-2 (red curve) is relative stable with the similar shape to its original $\mathrm{CV}$ curve (blue curve). Notably, the $D_{\mathrm{ClO}_{4}^{-}}$value at $\sim 3.2 \mathrm{~V}$ shows an obvious increase and shifts to the low voltage, further demonstrating the improved electrochemical reaction kinetics from the advantageous leaf-on-branch structure. According to Equation (2), the $b$-value could be obtained to qualitatively estimate the capacitive contributions and reaction kinetics $[41,42]$.

$i=a v^{b}$,

when the $b$ value is close to 0.5 , it presents diffusion-controlled behaviors. When the $b$ value is near 1.0, it indicates fast kinetics controlled by pseudo-capacitive behaviors. By the linear fitting of $\log (i) v s . \log (v)$, the $b$ values of CNF@PTPAn-2 and PTPAn-C were calculated to be 0.98 and 0.89 , respectively (Fig. 4c). Obviously, the electrochemical properties of active PTPAn are mainly contributed by the surface pseudo-capacitive behaviors. Furthermore, the larger $b$ value for CNF@PTPAn suggests the 
facilitated capacitive kinetics. The capacitive contribution ratio was further quantitatively calculated by Equations (3 and 4):

$i=k_{1} v+k_{2} v^{1 / 2}$,

$i / v^{1 / 2}=k_{1} v^{1 / 2}+k_{2}$.

In Fig. $4 \mathrm{~d}$, the ratio of the pseudo-capacitive contribution for CNF@PTPAn-2 is $85 \%$ at $2.0 \mathrm{mV} \mathrm{s}^{-1}$, higher than that of PTPAn-C (83.2\%). Additionally, the pseudo-capacitive contributions of the electrodes at various scan rates were also calculated. As shown in Fig. 4e and Fig. S8d-i, the pseudocapacitive contribution of CNF@PTPAn-2 shows gradual rise with increasing scan rates, always being higher than those of PTPAn-C electrode, strongly indicating the excellent rate capacity [43].

The detailed interfacial properties of the CNF@PTPAn cathode were further analyzed by EIS. As shown in Fig. 4f, the Nyquist plots consist of a semicircle in the high-frequency region and the sloping line in the low-frequency region. It is related to the charge transfer resistance $\left(R_{\mathrm{ct}}\right)$ at the electrolyte/ electrode interface and ion diffusion in the solid electrode $\left(Z_{\mathrm{w}}\right)$, corresponding to the equivalent circuit diagram in the inset. After fitting of the plots, $R_{\mathrm{ct}}$ of CNF@PTPAn-2 is $120 \Omega$, much smaller than that of PTPAn-C (419.6 $\Omega$ ). Fig. $4 \mathrm{~g}$ presents the linear relationship between $Z^{\prime}$ and $\omega^{-1 / 2}$, in which the slope $(\sigma)$ could be used to calculate the ion diffusion coefficient value based on Equations (5-7).

$\omega=2 \pi f$,

$Z^{\prime}=R+\sigma \omega^{-1 / 2}$,

$D=0.5 R^{2} T^{2} / A^{2} n^{4} F^{4} C^{2} \sigma^{2}$.

Thus, the $D$ value of CNF@PTPAn-2 was calculated as $3.98 \times$ $10^{-10} \mathrm{~cm}^{2} \mathrm{~s}^{-1}$, larger than that of the PTPAn-C powder electrode $\left(1.50 \times 10^{-10} \mathrm{~cm}^{2} \mathrm{~s}^{-1}\right)$. These results further confirm the faster electron/ion transport in CNF@PTPAn-2. Observed from the Bode-phase angle plot (Fig. 4h), the absolute phase angle of CNF@PTPAn-2 at $0.01 \mathrm{~Hz}$ is $41.9^{\circ}$, higher than that of PTPAn-C $\left(8.8^{\circ}\right)$, indicating the shorter ion diffusion length and lower electrical resistance [44]. Moreover, the phase angle of $-45^{\circ}$ is always regarded as a crucial standard to evaluate the capacitive behaviors. The corresponding frequencies are 3833 and $317 \mathrm{~Hz}$ for CNF@PTPAn-2 and PTPAn-C, respectively. The larger frequency for CNF@PTPAn-2 also reveals the improved rate capability. According to Equations (8 and 9), the real capacitance $\left(C^{\prime}\right)$ and imaginary capacitance $\left(C^{\prime \prime}\right)$ are displayed in Fig. S9a, b.

$C^{\prime}(\omega)=-Z^{\prime \prime}(\omega) / \omega[Z(\omega)]^{2}$,

$C^{\prime \prime}(\omega)=Z^{\prime}(\omega) / \omega[Z(\omega)]^{2}$.

As is known, $C^{\prime}$ is related to the feature of the electrode/ electrolyte interface [45]. For the function curve of $C^{\prime}$ versus frequency, at the low frequency, the improved active surface of electrode is accessible by the electrolyte ions, which will result in a large real capacitance. At a low frequency of $0.01 \mathrm{~Hz}$, the CNF@PTPAn-2 electrode shows a higher $C^{\prime}\left(33.4 \mathrm{Fg}^{-1}\right)$, about seven times that of PTPAn-C $\left(4.4 \mathrm{~F} \mathrm{~g}^{-1}\right)$, indicating its better energy-storage ability. With the increase of frequency, the $C^{\prime}$ values of CNF@PTPAn-2 have a sharp decline. At $0.03 \mathrm{~Hz}, \mathrm{C}^{\prime}$ of the CNF@PTPAn-2 electrode retains 40\% of its maximum capacitance, while the retention of PTPAn-C electrode is only
24\%. Compared with PTPAn-C, the decreasing rate of $C^{\prime}$ for CNF@PTPAn-2 is relatively slow, suggesting the fast ion-diffusion rate on the surface. Hence, the enlarged contact area between the electrode and electrolyte is beneficial to deepening the capacity reaction with improved utilization of active PTPAn materials. Moreover, the relatively large $C^{\prime \prime}\left(37.2 \mathrm{Fg}^{-1}\right)$ was observed for CNF@PTPAn-2, further demonstrating its faster surface reactions. In Fig. S9c, the admittance plots are detected. The highest point $\left(-Y^{\prime \prime}\right)$ of CNF@PTPAn-2 is obtained as $0.55 \mathrm{~S}$, also higher than that of PTPAn-C (0.04S), indicating the superior electronic conductivity [46].

\section{Structural stability of the free-standing CNF@PTPAn cathode}

The electroactive PTPAn, with open chain structure and fast doping/dedoping anion reaction mechanism (Fig. S10a), has been regarded as a promising cathode for high-power SIBs. The electrochemical reaction mechanism of CNF@PTPAn was explored by ex-situ FT-IR analysis on the electrodes at different charge/discharge states (Fig. S10b). Fig. S10c shows two peaks at 1592 and $1550 \mathrm{~cm}^{-1}$ of CNF@PTPAn when charged to $4.0 \mathrm{~V}$, indicating two kinds of $\mathrm{C}=\mathrm{C}$ ring stretching which are assigned to the typical semi-quinoid structure in PTPAn [36]. In addition, the characteristic peak from the $\mathrm{C}-\mathrm{N}$ region has a small shift to the lower wavenumber while a broad peak at about $1100 \mathrm{~cm}^{-1}$ is ascribed to the $\mathrm{ClO}_{4}^{-}$anion, implying the formation of $\mathrm{N}^{+} \mathrm{ClO}_{4}^{-}$ in PTPAn [10]. At the full discharged state of $2.0 \mathrm{~V}$, CNF@PTPAn displays the similar FT-IR spectrum to its pristine state, demonstrating the complete reversible $\mathrm{ClO}_{4}^{-}$anion release from PTPAn. Generally, the efficient charge transfer is crucial to redox reactions. As is known, the traditional casting PTPAn-C electrode, with bulk PTPAn particles and long electron pathway, would cause low utilization of the active PTPAn and adverse polarization, thus bringing about insufficient redox reactions. Inspired by the photosynthesis of plants, the unique leaf-onbranch structure can provide rapid electron and ion transport, which will contribute to the excellent structural stability of CNF@PTPAn during long cycling. First, the PTPAn-leaves grown on CNF-branch could improve their contact area with the electrolyte and expose more electroactive sites. Second, the CNF core with good conductivity can ensure the rapid electron migration during the redox reaction process. Third, the favorable electrolyte wettability enables fast anion $\left(\mathrm{ClO}_{4}^{-}\right)$doping/ dedoping. As a result, the leaf-on-branch structure is kept well after 100 cycles at the current density of $50 \mathrm{~mA} \mathrm{~g}^{-1}$, in which PTPAn nanosheets are still firmly anchored on the CNF (Fig. S11). This is ascribed to the stable coupling effect between CNF and PTPAn through $\pi-\pi$ interactions [47,48], which is confirmed by XPS results (Fig. S12).

\section{Electrochemical performance of flexible sodium-ion full cell}

To further explore the practical application of the CNF@PTPAn cathode, the flexible full cell of CNF@PTPAn//CNF was assembled by directly using CNF@PTPAn-2 membrane as the cathode and CNF membrane as the anode (Fig. 5a). With good mechanical strength and high conductivity, the free-standing CNF anode delivers stable specific discharge capacities for the half cell (Fig. S13). Moreover, it is chosen as the substrate material to improve the electrochemical properties of PTPAn cathode with fast ion/electron migration. Therefore, the full cell shows sloping voltage curves at different current densities from 

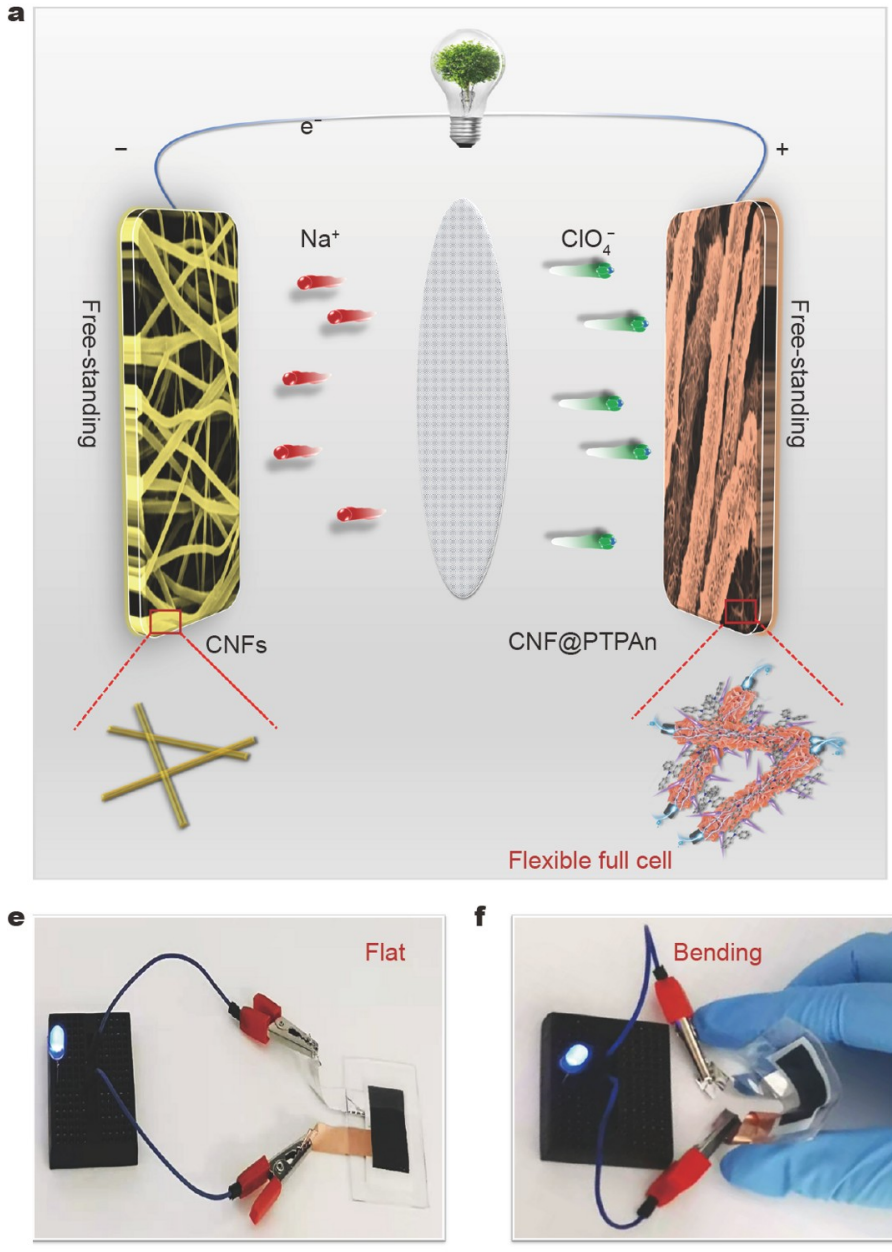

f

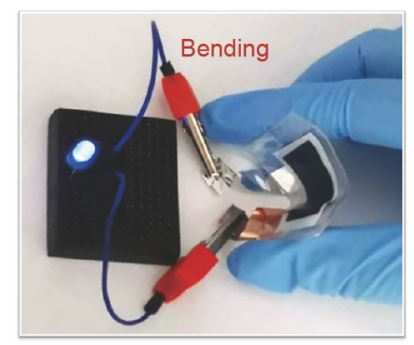

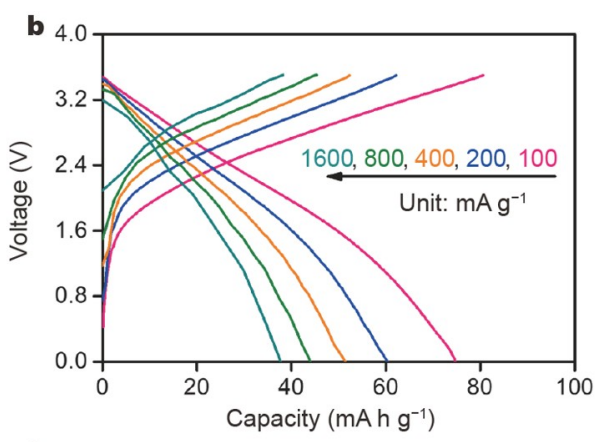
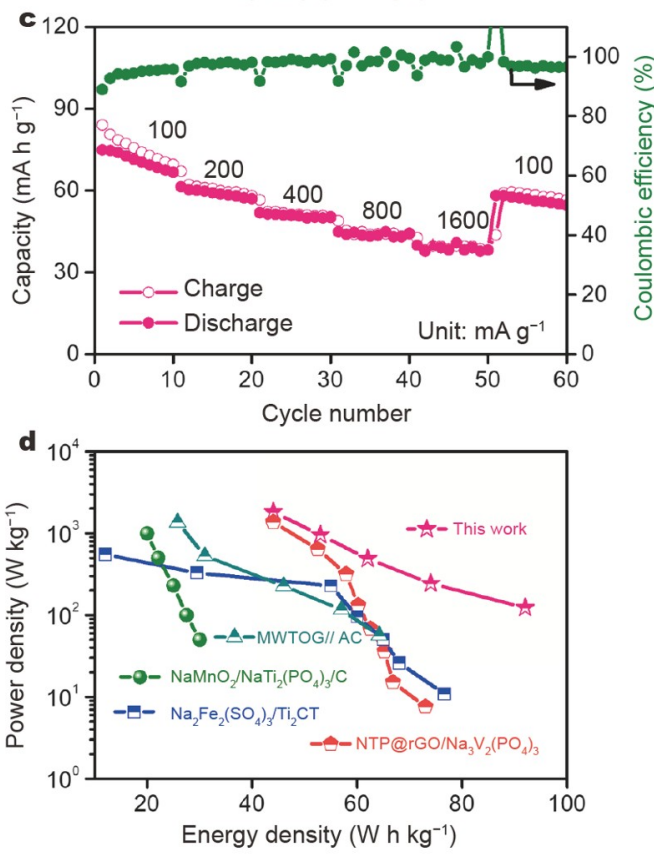

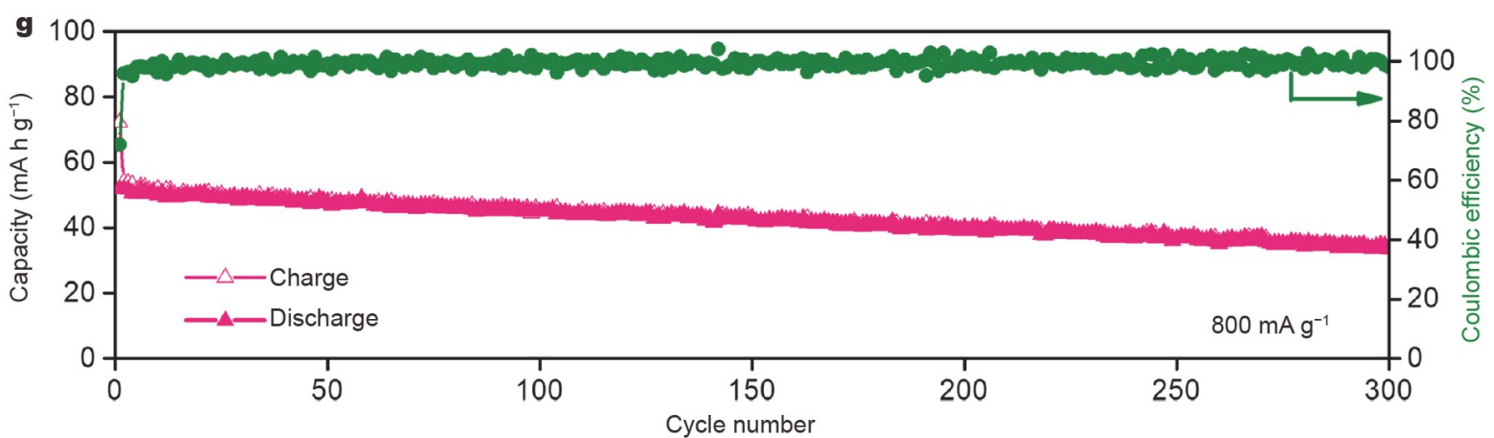

Figure 5 Electrochemical performance of the CNF@PTPAn//CNF full cell. (a) Schematic illustration of the flexible full cell assembled with CNF@PTPAn as the cathode and CNFs as the anode. (b) Charge/discharge curves and (c) rate performances of the cell at different current densities in the voltage range of 0.01-3.5 V. (d) Ragone plots of this work compared with the representative sodium-ion storage devices in literature. Photographs of the flexible full cell that light up an LED lamp at (e) flat and (f) bending states. (g) Long cycling performance of the cell at the current density of $800 \mathrm{~mA} \mathrm{~g}^{-1}$.

0.01 to $3.5 \mathrm{~V}$ with excellent reversibility (Fig. 5b). The CNF@PTPAn-2 electrode in the full cell exhibits the discharge capacities of $74.7,60.3,51.4,44.0$ and $37.8 \mathrm{~mA} \mathrm{~h} \mathrm{~g}^{-1}$ at the current densities of $100,200,400,800$ and $1600 \mathrm{~mA} \mathrm{~g}^{-1}$, respectively (Fig. 5c). Based on the total mass of active materials, the energy and power densities of the CNF@PTPAn//CNF full cell are obtained from the discharge curves (Fig. S14). As shown in Fig. $5 \mathrm{~d}$, the specific energy of the full cell reaches $92 \mathrm{~W} \mathrm{~h} \mathrm{~kg}^{-1}$ at the power density of $123 \mathrm{~W} \mathrm{~kg}^{-1}\left(100 \mathrm{~mA} \mathrm{~g}^{-1}\right)$, while a maximum power density of $1830 \mathrm{~W} \mathrm{~kg}^{-1}\left(1600 \mathrm{mAg}^{-1}\right)$ can be achieved with the energy density of $44 \mathrm{~W} \mathrm{~h} \mathrm{~kg}^{-1}$, much higher than those of many recently reported sodium-ion storage devices [49-52].

Moreover, the flexible full cell can successfully make a light emitting diode (LED) lamp lighted under different conditions of flat (Fig. 5e) and bending (Fig. 5f) states, implying its promising applications for flexible devices. Especially, the full cell still keeps a capacity of $33.5 \mathrm{~mA} \mathrm{~h} \mathrm{~g}^{-1}$ at the high current density of $800 \mathrm{~mA} \mathrm{~g}^{-1}$ with a coulombic efficiency of $99 \%$ after 300 cycles, corresponding to the energy density of $60 \mathrm{~W} \mathrm{~h} \mathrm{~kg}^{-1}$ at the power density of $938 \mathrm{~W} \mathrm{~kg}^{-1}$ (Fig. 5g). Thus, the CNF@PTPAn//CNF full cell demonstrates good energy storage performances and promising applications in the advanced flexible devices. 


\section{CONCLUSIONS}

In summary, the leaf-on-branch like CNF@PTPAn composite membranes were fabricated via the simple electrospinning and in-situ polymerization processes to behave as free-standing cathodes for high-performance SIBs. Meanwhile, the formation mechanism of PTPAn-leaf grown on CNF-branch was systematically explored. The tailored CNF@PTPAn composites possess the favorable electrolyte wettability, large electroactive surface area and high electronic conductivity, leading to rapid kinetics and enhanced electrochemical reaction process. As a result, the optimized CNF@PTPAn cathode exhibits a high reversible capacity of $105 \mathrm{~mA} \mathrm{~h} \mathrm{~g}^{-1}$ at the current density of $50 \mathrm{~mA} \mathrm{~g}^{-1}$ and excellent rate capability of $78 \mathrm{~mA} \mathrm{~h}^{-1}$ even at a high current density of $400 \mathrm{~mA} \mathrm{~g}^{-1}$ after 500 cycles in the half cell. When paired with the CNF anode, the flexible CNF@PTPAn//CNF full cell could achieve a high energy density of $60 \mathrm{~W} \mathrm{~h} \mathrm{~kg}^{-1}$ at the power density of $938 \mathrm{~W} \mathrm{~kg}^{-1}$.

\section{Received 18 March 2021; accepted 28 May 2021;} published online 27 July 2021

1 Palomares V, Serras $\mathrm{P}$, Villaluenga I, et al. $\mathrm{Na}$-ion batteries, recent advances and present challenges to become low cost energy storage systems. Energy Environ Sci, 2012, 5: 5884

2 Ma M, Yao Y, Wu Y, et al. Progress and prospects of transition metal sulfides for sodium storage. Adv Fiber Mater, 2020, 2: 314-337

3 Massé RC, Uchaker E, Cao G. Beyond Li-ion: Electrode materials for sodium- and magnesium-ion batteries. Sci China Mater, 2015, 58: 715766

4 Li W-, Han C, Wang W, et al. Commercial prospects of existing cathode materials for sodium ion storage. Adv Energy Mater, 2017, 7: 1700274

5 Zhao C, Chen Z, Wang W, et al. In situ electropolymerization enables ultrafast long cycle life and high-voltage organic cathodes for lithium batteries. Angew Chem Int Ed, 2020, 59: 11992-11998

6 Xiang X, Zhang K, Chen J. Recent advances and prospects of cathode materials for sodium-ion batteries. Adv Mater, 2015, 27: 5343-5364

7 Cao X, Liu J, Zhu L, et al. Polymer electrode materials for high-performance lithium/sodium-ion batteries: A review. Energy Technol, 2019, 7: 1800759

8 Zhou G, Mo L, Zhou C, et al. Flexible naphthalene-based polyimide nanofiber cathode with hierarchical micro/nanoporous structure for high-performance organic sodium-ion batteries. Compos Commun, 2020, 22: 100490

9 Xiong $\mathrm{P}$, Yin $\mathrm{H}$, Chen $\mathrm{Z}$, et al. Thiourea-based polyimide/RGO composite cathode: A comprehensive study of storage mechanism with alkali metal ions. Sci China Mater, 2020, 63: 1929-1938

10 Han $\mathrm{H}, \mathrm{Lu} \mathrm{H}$, Jiang $\mathrm{X}$, et al. Polyaniline hollow nanofibers prepared by controllable sacrifice-template route as high-performance cathode materials for sodium-ion batteries. Electrochim Acta, 2019, 301: 352 358

11 Luo W, Allen M, Raju V, et al. An organic pigment as a high-performance cathode for sodium-ion batteries. Adv Energy Mater, 2014, 4: 1400554

12 Yang J, Xiong P, Shi Y, et al. Rational molecular design of benzoquinone-derived cathode materials for high-performance lithium-ion batteries. Adv Funct Mater, 2020, 30: 1909597

13 Zhao R, Zhu L, Cao Y, et al. An aniline-nitroaniline copolymer as a high capacity cathode for Na-ion batteries. Electrochem Commun, 2012, 21: 36-38

14 Zhou M, Xiong Y, Cao Y, et al. Electroactive organic anion-doped polypyrrole as a low cost and renewable cathode for sodium-ion batteries. J Polym Sci B Polym Phys, 2013, 51: 114-118

15 Zhao Q, Whittaker AK, Zhao XS. Polymer electrode materials for sodium-ion batteries. Materials, 2018, 11: 2567

16 Deng W, Liang X, Wu X, et al. A low cost, all-organic Na-ion battery based on polymeric cathode and anode. Sci Rep, 2013, 3: 2671

17 Fan L, Liu Q, Xu Z, et al. An organic cathode for potassium dual-ion full battery. ACS Energy Lett, 2017, 2: 1614-1620

18 Dong $\mathrm{X}, \mathrm{Yu} \mathrm{H}, \mathrm{Ma} \mathrm{Y}$, et al. All-organic rechargeable battery with reversibility supported by "water-in-salt" electrolyte. Chem Eur J, 2017, 23: $2560-2565$

19 Feng JK, Cao YL, Ai XP, et al. Polytriphenylamine: A high power and high capacity cathode material for rechargeable lithium batteries. J Power Sources, 2008, 177: 199-204

20 Chen Z, Su C, Zhu X, et al. Micro-/mesoporous conjugated polymer based on star-shaped triazine-functional triphenylamine framework as the performance-improved cathode of Li-organic battery. J Polym Sci Part A-Polym Chem, 2018, 56: 2574-2583

$21 \mathrm{Su} \mathrm{C}$, Ye YP, Bu XD, et al. Preparation and properties of polytriphenylamine/multi-walled carbon nanotube composite as a cathode material for Li-ion batteries. Adv Mater Res, 2011, 335-336: 1512-1515

22 She QJ, Wei ZK, Zheng MS, et al. Electrochemical performance of polytriphenylamine as a novel non-aqueous supercapcitor cathode material. Electrochem, 2011, 17: 53-56

23 Yuan $\mathrm{W}$, Wang $\mathrm{B}, \mathrm{Wu} \mathrm{H}$, et al. A flexible 3D nitrogen-doped carbon foam@CNTs hybrid hosting $\mathrm{TiO}_{2}$ nanoparticles as free-standing electrode for ultra-long cycling lithium-ion batteries. J Power Sources, 2018, 379: 10-19

24 Sun Z, Tan K, Hou L, et al. Coordination polymer nanowires/reduced graphene oxide paper as flexible anode for sodium-ion batteries. Sci China Mater, 2020, 63: 1966-1972

25 Xiong G, He P, Lyu Z, et al. Bioinspired leaves-on-branchlet hybrid carbon nanostructure for supercapacitors. Nat Commun, 2018, 9: 790

26 Li H, Zhou Q, Liu F, et al. Biomimetic design of ultrathin edge-riched FeOOH@carbon nanotubes as high-efficiency electrocatalysts for water splitting. Appl Catal B-Environ, 2019, 255: 117755

27 Takahashi C, Moriya S, Fugono N, et al. Preparation and characterization of poly(4-alkyltriphenylamine) by chemical oxidative polymerization. Synth Met, 2002, 129: 123-128

28 Ni W, Cheng J, Li X, et al. Polymeric cathode materials of electroactive conducting poly(triphenylamine) with optimized structures for potential organic pseudo-capacitors with higher cut-off voltage and energy density. RSC Adv, 2015, 5: 9221-9227

29 Ali Z, Asif M, Huang X, et al. Hierarchically porous $\mathrm{Fe}_{2} \mathrm{CoSe}_{4}$ binarymetal selenide for extraordinary rate performance and durable anode of sodium-ion batteries. Adv Mater, 2018, 30: 1802745

30 Weng W, Kurihara R, Wang J, et al. Electrospun carbon nanofiberbased composites for lithium-ion batteries: Structure optimization towards high performance. Compos Commun, 2019, 15: 135-148

31 Hu G, Zhang X, Liu X, et al. Strategies in precursors and post treatments to strengthen carbon nanofibers. Adv Fiber Mater, 2020, 2: 4663

32 Zhang L, Huang Y, Zhang Y, et al. Flexible electrospun carbon nanofiber@NiS core/sheath hybrid membranes as binder-free anodes for highly reversible lithium storage. Adv Mater Interfaces, 2016, 3: 1500467

33 Louarn G, Lapkowski M, Quillard S, et al. Vibrational properties of polyanilineisotope effects. J Phys Chem, 1996, 100: 6998-7006

34 Boyer MI, Quillard S, Rebourt E, et al. Vibrational analysis of polyaniline: A model compound approach. J Phys Chem B, 1998, 102: 7382-7392

35 Luo W, Schardt J, Bommier C, et al. Carbon nanofibers derived from cellulose nanofibers as a long-life anode material for rechargeable sodium-ion batteries. J Mater Chem A, 2013, 1: 10662-10666

36 Kvarnström C, Petr A, Damlin P, et al. Raman and FTIR spectroscopic characterization of electrochemically synthesized poly(triphenylamine), PTPA. J Solid State Electrochem, 2002, 6: 505-512

37 Zhang J, Yue L, Kong Q, et al. Sustainable, heat-resistant and flameretardant cellulose-based composite separator for high-performance lithium ion battery. Sci Rep, 2014, 4: 3935

38 Ni Q, Bai Y, Li Y, et al. 3D electronic channels wrapped large-sized $\mathrm{Na}_{3} \mathrm{~V}_{2}\left(\mathrm{PO}_{4}\right)_{3}$ as flexible electrode for sodium-ion batteries. Small, 2018, 14: 1702864 
39 Li $\mathrm{H}, \mathrm{Yu} \mathrm{X}$, Bai $\mathrm{Y}$, et al. Effects of $\mathrm{Mg}$ doping on the remarkably enhanced electrochemical performance of $\mathrm{Na}_{3} \mathrm{~V}_{2}\left(\mathrm{PO}_{4}\right)_{3}$ cathode materials for sodium ion batteries. J Mater Chem A, 2015, 3: 9578-9586

40 Ge P, Zhang L, Zhao W, et al. Interfacial bonding of metal-sulfides with double carbon for improving reversibility of advanced alkali-ion batteries. Adv Funct Mater, 2020, 30: 1910599

41 Salanne M, Rotenberg B, Naoi K, et al. Efficient storage mechanisms for building better supercapacitors. Nat Energy, 2016, 1: 16070

42 Choi C, Ashby DS, Butts DM, et al. Achieving high energy density and high power density with pseudocapacitive materials. Nat Rev Mater, 2019, 5: 5-19

43 Li P, Chen C, Ding S, et al. Controllable deposition of $\mathrm{FeV}_{2} \mathrm{~S}_{4}$ in carbon fibers for sodium-ion storage with high capacity and long lifetime. Sci China Mater, 2021, 64: 1355-1366

44 Mahankali K, Thangavel NK, Ding Y, et al. Interfacial behavior of water-in-salt electrolytes at porous electrodes and its effect on supercapacitor performance. Electrochim Acta, 2019, 326: 134989

45 Taberna PL, Simon P, Fauvarque JF. Electrochemical characteristics and impedance spectroscopy studies of carbon-carbon supercapacitors. J Electrochem Soc, 2003, 150: A292

46 Ates $\mathrm{M}$, Kuzgun O, Yildirim $\mathrm{M}$, et al. $\mathrm{rGO} / \mathrm{MnO}_{2} /$ polyterthiophene ternary composite: Pore size control, electrochemical supercapacitor behavior and equivalent circuit model analysis. J Polym Res, 2020, 27: 202

47 Zhu X, Ni Z, Dong L, et al. In-situ modulation of interactions between polyaniline and graphene oxide films to develop waterborne epoxy anticorrosion coatings. Prog Org Coatings, 2019, 133: 106-116

48 Luo SW, Gu R, Shi P, et al. $\pi-\pi$ interaction boosts catalytic oxygen evolution by self-supporting metal-organic frameworks. J Power Sources, 2020, 448: 227406

49 Fang Y, Xiao L, Qian J, et al. 3D graphene decorated $\mathrm{NaTi}_{2}\left(\mathrm{PO}_{4}\right)_{3}$ microspheres as a superior high-rate and ultracycle-stable anode material for sodium ion batteries. Adv Energy Mater, 2016, 6: 1502197

50 Wang X, Kajiyama S, Iinuma H, et al. Pseudocapacitance of MXene nanosheets for high-power sodium-ion hybrid capacitors. Nat Commun, 2015, 6: 6544

51 Le Z, Liu F, Nie P, et al. Pseudocapacitive sodium storage in mesoporous single-crystal-like $\mathrm{TiO}_{2}$-graphene nanocomposite enables highperformance sodium-ion capacitors. ACS Nano, 2017, 11: 2952-2960

52 Hou Z, Li X, Liang J, et al. An aqueous rechargeable sodium ion battery based on a $\mathrm{NaMnO}_{2}-\mathrm{NaTi}_{2}\left(\mathrm{PO}_{4}\right)_{3}$ hybrid system for stationary energy storage. J Mater Chem A, 2015, 3: 1400-1404

Acknowledgements This work was financially supported by the National Natural Science Foundation of China (22075042), the Natural Science Foundation of Shanghai (20ZR1401400 and 18ZR1401600), the Shanghai Scientific and Technological Innovation Project (18JC1410600), the Fundamental Research Funds for the Central Universities and DHU Distinguished Young Professor Program (LZB2021002).

Author contributions Mo L, Zhou G and Miao Y conceived the idea. Mo L performed the experiments, analyzed the data and wrote the manuscript. Zhou G performed partial experiments and tests. Ge P contributed to the schematic diagrams partly and guided the manuscript. Miao Y contributed to the theoretical analysis, supervision and editing. Liu $\mathrm{T}$ contributed to the supervision and editing. All authors contributed to the general discussion.

Conflict of interest The authors declare that they have no conflict of interest.

Supplementary information version of the paper.

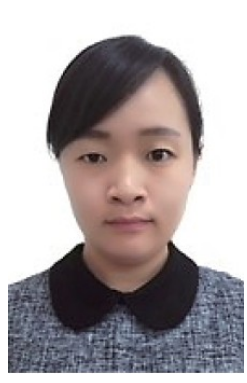

Lulu Mo received her Master's degree in Chemistry from Henan University of Technology in 2017. Currently, she is a $\mathrm{PhD}$ candidate under the supervision of Prof. Tianxi Liu at the College of Materials Science and Engineering, Donghua University. Her research focuses on the design and synthesis of novel carbon nanofiber composites for lithium/sodium ion batteries.

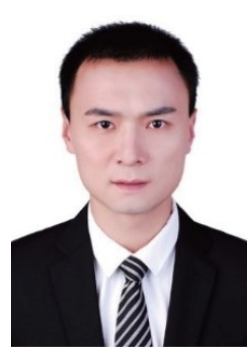

Peng Ge is an associate professor at the School of Minerals Processing and Bioengineering, Central South University. He received his PhD at the Central South University in 2019. His research interests are the development of new materials derived from mineral chemistry and their applications in electrochemical energy storage and conversion.

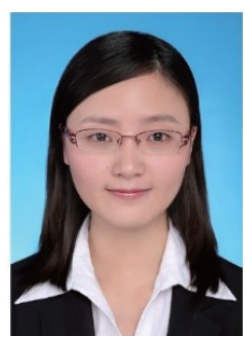

Yue-E Miao received her BS degree from the Southeast University in 2010 and $\mathrm{PhD}$ degree from Fudan University in 2015. She is now an associate professor at the College of Materials Science and Engineering, Donghua University. Her research interests mainly focus on high-performance organic fiber electrodes/ separators, carbon nanofiber composites, as well as their applications in electrochemical energy storage devices (such as $\mathrm{Li} / \mathrm{Na}$-ion batteries and $\mathrm{Li}-\mathrm{S}$ batteries).

Tianxi Liu obtained his BS degree from Henan University (1992) and PhD degree from Changchun Institute of Applied Chemistry, Chinese Academy of Sciences (1998). He is currently a full professor at the College of Materials Science and Engineering, Donghua University. His main research interests include polymer nanocomposites, organic/inorganic hybrid materials, nanofibers and their composites, and advanced energy materials for energy conversion and storage.

\title{
原位聚合法构筑柔性聚三苯胺正极材料助力高性能 钠离子电池
}

\author{
莫璐璐 ${ }^{1}$, 周刚勇 ${ }^{1}$, 葛鹏 $3^{*}$, 缪月娥 ${ }^{*}$, 刘天西 ${ }^{1,2 *}$
}

摘要 聚三苯胺(PTPAn)因具有优异的氧化还原可逆性和结构多样性, 被认为是极有前景的钠离子电池正极材料之一. 然而, 在实际应用中, 大块体的PTPAn材料仍存在团聚和工作容量低的问题. 本文通过原位 聚合法将树叶状的PTPAn纳米片均匀地生长在碳纳米纤维 (CNFs) 表 面, 构建了一种自支撑的CNF@PTPAn复合电极. 本文还系统探索了 CNF@PTPAn复合材料中枝叶结构的形成机理, 证实了原位反应的氧 化速率和生长程度对调控复合电极的形貌及其活性物质含量起了关键 作用. 通过截止容量分析发现, PTPAn活性材料与导电CNFs之间的高 效复合可以提供快速的电子/离子传输通道, 有助于增强电极的深度电 化学反应过程. 由优化后的CNF@PTPAn复合材料所组装的钠离子半 电池具有高比容量和稳定的倍率性能. 在 $50 \mathrm{~mA} \mathrm{~g}^{-1}$ 的电流密度下可达 $105 \mathrm{~mA} \mathrm{~h} \mathrm{~g}^{-1}$, 甚至在 $400 \mathrm{~mA} \mathrm{~g}^{-1}$ 的高电流密度下循环 500 圈后仍能保持 $78 \mathrm{~mA} \mathrm{~h} \mathrm{~g}^{-1}$ 的比容量. 动力学分析证明, 通过调控材料在低电压区域的 离子存储行为, 可以有效提升其电容主导的容量贡献和扩散系数. 同时, 以 CNF@PTPAn为正极和CNFs 为负极组装的柔性CNF基全电池, 在 $938 \mathrm{~W} \mathrm{~kg}^{-1}$ 功率密度下表现出 $60 \mathrm{~W} \mathrm{~h} \mathrm{~kg}^{-1}$ 的高能量密度. 基于此, 该设 计有望为获得先进的自支撑电极体系提供更多的可能性. 